\title{
Influence of Alcohol $\beta$-Fluorination on Hydrogen-Bond Acidity of Conformationally Flexible Substrates
}

\author{
J. Graton, ${ }^{*(a)}$ G. Compain, ${ }^{(b)}$ F. Besseau, ${ }^{(a)}$ E. Bogdan, ${ }^{(a)}$ J. M. Watts, ${ }^{(b)}$ L. Mtashobya, ${ }^{(b)}$ Z. Wang, ${ }^{(b)}$ A. \\ Weymouth-Wilson, ${ }^{(\mathrm{c})}$ N. Galland, ${ }^{(a)}$ J.-Y. Le Questel, ${ }^{*(a)}$ B. Linclau, ${ }^{*(b)}$
}

\begin{abstract}
Rational modulations of molecular interactions are of significant importance in compound properties optimization. We have previously shown that fluorination of conformationally rigid cyclohexanols leads to attenuation of their hydrogen-bond ( $\mathrm{H}$-bond) donating capacity $\left(\mathrm{p} K_{\mathrm{AHY}}\right)$ when $\mathrm{OH} \cdots \mathrm{F}$ intramolecular hydrogenbond (IMHB) interactions occur, as opposed to an increase in $\mathrm{p} K_{\mathrm{AHY}}$ due to the fluorine electronegativity. This work has now been extended to a wider range of aliphatic $\beta$-fluorohydrins with increasing degrees of conformational flexibility. We show that the -sometimes unexpected-observed differences in $\mathrm{p} K_{\mathrm{AHY}}$ between closely related diastereomers can be fully rationalized by subtle variations in populations of conformers able to engage in $\mathrm{OH} \cdots \mathrm{F}$ IMHB, as well as by the strength of these IMHBs. We also show that the Kenny theoretical $V_{a}(\mathrm{r})$ descriptor of $\mathrm{H}$-bond acidity accurately reflects the observed variations and a calibration equation extended to fluorohydrins is proposed. This work clearly underlines the importance of the weak $\mathrm{OH} \cdots \mathrm{F}$ IMHB in the modulation of alcohol $\mathrm{H}$ bond donating capacity.
\end{abstract}

\section{Introduction}

Fluorination of organic compounds is well known to affect chemical properties of adjacent functional groups, as well as physicochemical properties at the molecular level. ${ }^{[1]}$ In addition, a $\mathrm{C}-\mathrm{F}$ bond itself offers opportunities for weak attractive intermolecular interactions with protein residues, ${ }^{[2]}$ for example as weak hydrogen bond ( $\mathrm{H}$-bond) acceptor. ${ }^{[3]}$ The large fluorine electronegativity, resulting in a highly polarized $\mathrm{C}-\mathrm{F}$ bond and weakly-polarizable fluorine lone pairs, is at the origin of these

Dr. Jérôme Graton, Prof. Dr. Jean-Yves. Le Questel, Dr Elena Bogdan, Dr Nicolas Galland, Mr François Besseau CEISAM UMR CNRS 6230, Faculté des Sciences et des Techniques, Université de Nantes

2, rue de la Houssinière - BP 92208,44322 NANTES Cedex $3(F)$ Fax: (+3) 2511254 02, E-mail: jerome.graton@univ-nantes.fr, jean-yves.le-questel@univ-nantes.fr

Prof. Dr. Bruno Linclau, Dr Guillaume Compain, Mr Joseph M. Watts, Mr Lewis Mtashobya, Dr Zhong Wang

Chemistry, University of Southampton, Highfield, Southampton SO17 1BJ (UK)

Fax: (+44) 238059 7574, E-mail: bruno.linclau@soton.ac.uk

Dr Alex Weymouth-Wilson

Dextra Laboratories Ltd, The Science and Technology Centre,

Earley Gate, Whiteknights Road, Reading RG6 6BZ, UK

Supporting information for this article is given via a link at the end of the document effects, which have been amply exploited in many fields, especially in the biosciences. ${ }^{[1,4]}$

The impact of fluorination on Brønsted acid/base properties is well-understood: in general, fluorine introduction increases Brønsted acidity, and decreases Brønsted basicity, even if subtle effects may occur. ${ }^{[5]}$ On the other hand, the fluorine influence on $\mathrm{H}$-bond properties of adjacent functional groups has been shown to be less chemically intuitive. While the strong increase in $\mathrm{H}$-bond donating capacity ( $\mathrm{H}$-bond acidity) of polyfluorinated alcohols such as hexafluoroisopropanol (HFIP) and trifluoroethanol (TFE) has been well-documented, ${ }^{[6]}$ our work involving stereochemically defined, conformationally rigid fluorohydrins $^{[7]}$ (Figure 1) shows that monofluorination can lead to a decreased $\mathrm{OH} \mathrm{H}$-bond acidity on the $\mathrm{pK} \mathrm{AHY}_{\mathrm{AH}}$ scale, ${ }^{[6 \mathrm{cc}]}$ and that $\beta, \beta$-difluorination only leads to a modest increase. The $\mathrm{H}$ bond acidities were measured in $\mathrm{CCl}_{4}$ at $25^{\circ} \mathrm{C}$ by FTIR spectroscopy. ${ }^{[6]}$ Computationally obtained predictions of $\mathrm{H}$-bond properties, such as the Kenny $V_{a}(r)$ parameter for $\mathrm{H}$-bond acidities ${ }^{[8]}$ showed an excellent correlation with the experimental values. $^{[6 \mathrm{c}, 7]}$
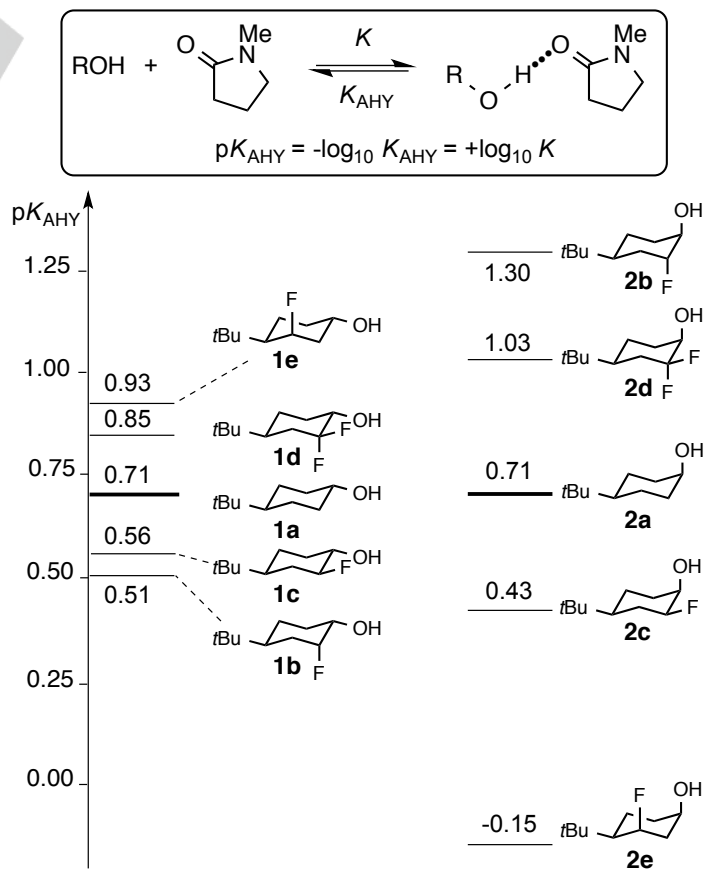

Figure 1. Experimental $\mathrm{H}$-bond acidities of conformationally restricted fluorohydrins. ${ }^{[7]}$

The changes in $\mathrm{pK}_{\mathrm{AHY}}$, shown in Figure 1, were explained as the result of a combination of the fluorine electronegativity, which increases $\mathrm{H}$-bond acidity (e.g. $\mathbf{2} \mathbf{b}$ vs $\mathbf{2 a}$ ), and of $\mathrm{OH} \cdots \mathbf{F}$ 
intramolecular hydrogen-bond (IMHB) interactions (e.g. 2c vs 2a), which have an attenuating effect. Indeed, after long debates ${ }^{[1,9]}$ the effective ability of fluorine to act as a H-bond acceptor, through inter- and intramolecular $\mathrm{OH} \cdots \mathrm{F}$ interactions, is now clearly established. ${ }^{[3]}$ We also noted that the effect of the fluorine electronegativity depended on the fluorohydrin dihedral angle. ${ }^{[10]}$

The conformational rigidity of the cyclohexane rings in the $\beta$ fluorohydrins shown in Figure 1 results in a fully defined fluorohydrin $\mathrm{F}-\mathrm{C}-\mathrm{C}-\mathrm{O}$ dihedral angle, with the rotation around the $\mathrm{C}-\mathrm{O}$ bond being the only relevant conformational flexibility feature. Following from this study, we have now investigated the influence of fluorination on the $\mathrm{H}$-bond acidities of $\beta$-fluorohydrin families 3-6 (Figure 2), the results of which are reported herein. These fluorinated compounds present various degrees of conformational flexibility related to the $\beta$-fluorohydrin $\mathrm{C}-\mathrm{C}$ bond: cyclohexanols 3 , with chair inversion leading to two possible $\beta$ fluorohydrin conformations; and substrates 4, 5, 6, with full fluorohydrin flexibility. However, in $\mathbf{4}$ and $\mathbf{5}$, the alcohol group has a fixed equatorial or axial position. We report their synthesis, the experimental determination of their $\mathrm{H}$-bond acidities, and the computational analyses of their conformational properties. Natural Bond Orbital (NBO) $)^{[11]}$ analyses, aimed to provide an accurate description of the different IMHB interactions occurring in the various fluorohydrins are included, as well as computations of the electrostatic potential $V_{a}(r)$ descriptor which is correlated to the experimental $\mathrm{H}$-bond acidity values. ${ }^{[3 \mathrm{~h}, 6 \mathrm{cc}, 7-8]}$ Finally, the relationship between the frequency shift, $\Delta v_{\mathrm{OH}}$, of the $v_{\mathrm{OH}}$ stretching vibration and $\mathrm{p} K_{\mathrm{AHY}}$ is discussed.

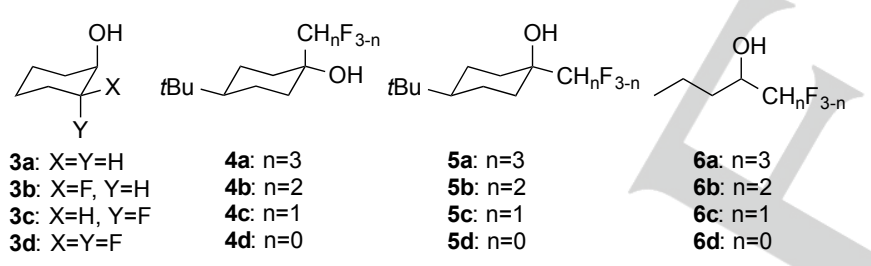

Figure 2. Structures of the $\beta$-fluorohydrins under study, with decreasing levels of conformational [fluorohydrin bond] restriction: cyclohexanols (series 3 ), $t$ butyl cyclohexanols (series $\mathbf{4}$ and $\mathbf{5}$ ), and pentan-2-ols (series 6).

\section{Experimental and Computational Results}

\section{Fluorohydrin synthesis}

The synthesis of compounds $\mathbf{3 - 5}$, and $\mathbf{6 d}$ was achieved according to the literature, and the synthesis of the novel compounds $\mathbf{6 b}$ and $\mathbf{6 c}$ was achieved using standard fluorination methodology. All synthesis and characterization details are provided in the Supporting Information.

\section{Theoretical conformational analysis}

A full description of the $\mathrm{H}$-bond properties of functional groups is innately connected with their thorough conformational analysis, ${ }^{[3 h, 12]}$ which was undertaken for the compounds under study by density functional theory (DFT) calculations. For a proper description of their structural features and the relative populations of the various conformers, the solvent effects $\left(\mathrm{CCl}_{4}\right.$ in the current experiments) were accounted for during geometry optimization. The main conformers results for 3-5 are shown in Table 1 (full data in the Supporting Information). Where appropriate, F...HO intramolecular distances are given.

For series 3, conformational nomenclature consists of descriptors that indicate whether the $\mathrm{OH}$ group is axial or equatorial, and that characterize the $\mathrm{H}-\mathrm{O}-\mathrm{C}-\mathrm{H}$ dihedral angle. The cis-fluorohydrin $\mathbf{3 b}$ is calculated to have a virtually equally distributed population between the two chair conformations (in $\mathrm{CCl}_{4}$, at $25{ }^{\circ} \mathrm{C}$ ), with a strong preponderance for the $A x_{-} g^{+}$ $(50 \%)$ and $E q_{-} t(45 \%)$ forms in which the $\mathrm{O}-\mathrm{H}$ and $\mathrm{C}-\mathrm{F}$ bonds are oriented parallel. The F...HO distances are just below $2.3 \AA$, up to $10 \%$ shorter than the sum of the fluorine and hydrogen van der Waals radii $(2.57 \AA){ }^{[13]}$ However, using NMR spectroscopic analysis at $-80^{\circ} \mathrm{C}$, Basso et al. found a conformational preference significantly in favor of the equatorial form in dichloromethane $(73 \%)$, acetone $(68 \%)$ and methanol $(75 \%){ }^{[14]}$ These differences likely originate from a temperature and solvent dependence. For the trans fluorohydrin $\mathbf{3 c}$, the chair conformation is strongly favored towards the gauche fluorohydrin arrangement, that is with both substituents in equatorial positions (total population: 93\%, see Table S1), and mainly as the $E q \_g^{+}$conformer (88\%). This is in good agreement with a previously published result ( $92 \%$ for the equatorial form) derived from the coupling constants measured by NMR spectroscopy in $\mathrm{CCl}_{4}$ solution. ${ }^{[15]}$ In the same solvent, ${ }^{[16]} \mathrm{a}$ population of $98 \%$ for the equatorial form was evaluated after deconvolution of the $v_{\mathrm{OH}}$ stretching band at $3614 \mathrm{~cm}^{-1}$ with a shoulder at $3633 \mathrm{~cm}^{-1}$. Similarly, the three major conformations of difluorinated 3d, $A x \_g^{+}(65 \%), E q \_g^{+}(18 \%)$ and Eq_t $(12 \%)$, corresponding to about $95 \%$ of the whole population, present one fluorine atom close to the hydroxyl group. For the IMHB conformers of both $\mathbf{3} \mathbf{c}$ and $\mathbf{3 d}$, all $\mathrm{OH} \cdots \cdot \mathrm{F}$ distances are larger than $2.3 \AA$.

For series 4 and $\mathbf{5}$, the two descriptors used for the monofluorinated derivatives relate to the $\mathrm{H}-\mathrm{O}-\mathrm{C}-\mathrm{CH}_{3}$ and $\mathrm{F}-$ $\mathrm{CH}_{2}-\mathrm{C}-\mathrm{O}$ dihedral angles, while for the difluoromethylated compounds, the second descriptor now relates to the $\mathrm{H}_{-}-\mathrm{CF}_{2}-\mathrm{C}-$ $\mathrm{O}$ dihedral angle. In these compounds, the hydroxyl group is mainly found as part of a gauche fluorohydrin conformation, whatever the degree of fluorination. However, it is worth noting that for the non-fluorinated $\mathbf{4 a}$ and $\mathbf{5 a}$, this preference is partly due to the higher degeneracy of the gauche form. Conversely, for the mono-, di-, and trifluorinated derivatives, these $G$ conformers essentially benefit from the stabilizing IMHB interactions, and it is interesting to note the significant difference of the exocyclic $\mathrm{CH}_{2} \mathrm{~F}$ conformations of $\mathbf{4 a}, 5 \mathbf{a}$ with the equivalent compounds without the hydroxyl group, as recently described in detail by Huchet et al. ${ }^{[17]}$ Their populations indeed reach at least $85 \%$ in $\mathrm{CCl}_{4}$, except for compound $\mathbf{5 b} \mathbf{b}(72 \%$ for the $G \_g^{+}$conformer). Interestingly, the $\mathrm{OH} \cdots \mathrm{F}$ distances in $\mathbf{4 c / d}$ are longer compared to those in $\mathbf{5} \mathbf{c} / \mathbf{d}$, and the proportion of IMHB conformers increases from $\mathbf{5 b}$ to $\mathbf{5 d}$, and to a lesser extent from $\mathbf{4 b}$ to $\mathbf{4 d}$.

Without any structural constraint, the conformational landscape of the pentan-2-ol derivatives 6a-d is very diverse, with a large number of conformers ( 15 for $6 \mathbf{a}, 23$ for $\mathbf{6 b}, 20$ for 
Table 1. Calculated parameters related to the conformers of 3-5 in $\mathrm{CCl}_{4}$ medium at the IEFPCM-MPWB1K/6-31+G(d,p) level of theory.

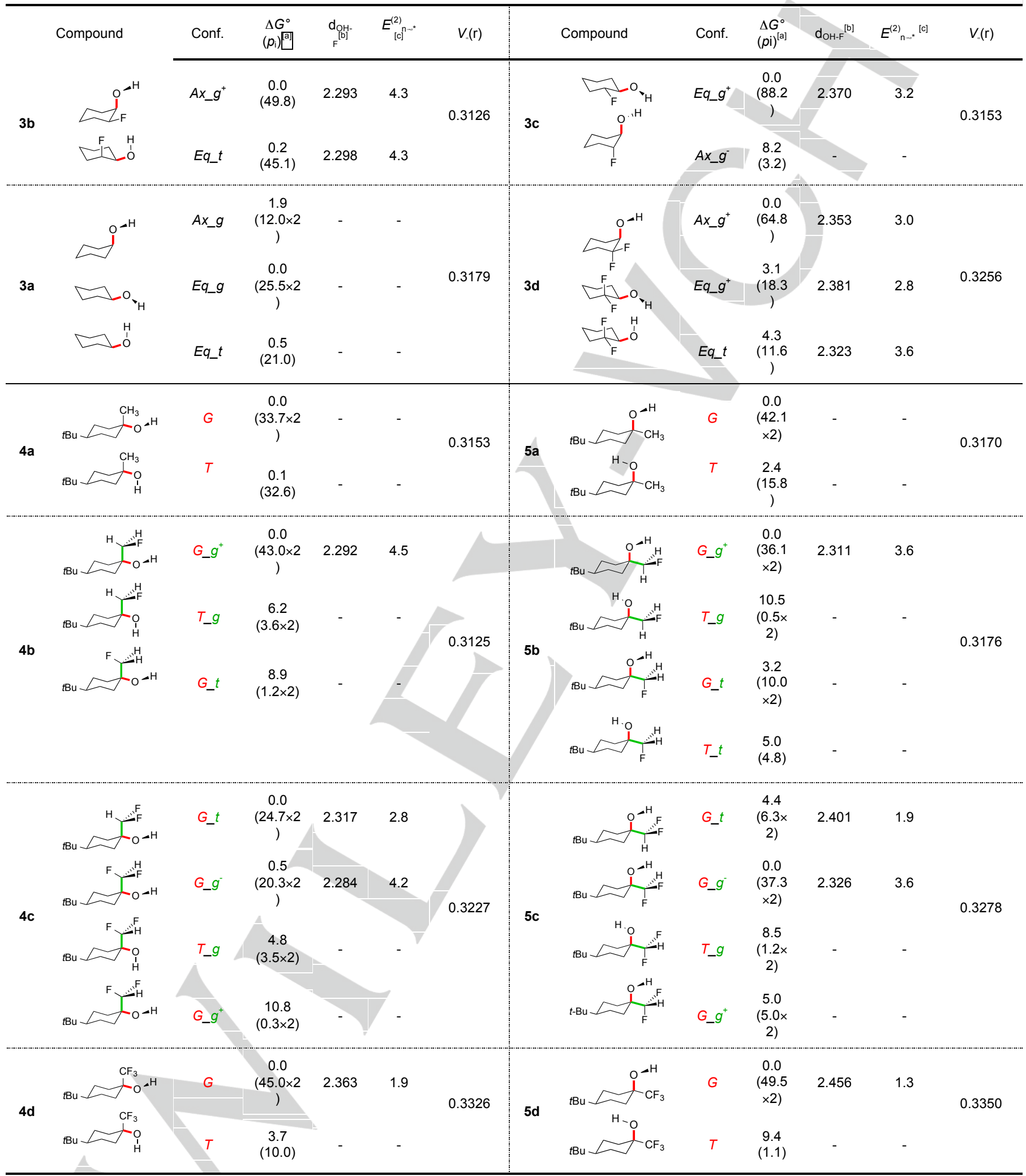

[a] in $\mathrm{KJ} \mathrm{mol}^{-1}$ (\%). [b] in A. [c] in $\mathrm{KJ} \mathrm{mol}^{-1}$. [d] in a.u. [e] calculated from eq. (2). 
6c, and 9 for $6 \mathrm{~d}$ ) found within an energetic range of $10 \mathrm{~kJ} \mathrm{~mol}^{-1}$ (see Table S4). Nevertheless, the following trends can be drawn: the proportion of IMHB conformers steadily increases from $\mathbf{6 b}$ to $\mathbf{6 d}(80 \%, 92 \%$, and $99.7 \%)$, despite a concomitant lengthening of the $\mathrm{OH} \cdots \cdot \mathrm{F}$ distances (the weighted values are $2.326,2.350$ and $2.450 \AA$, respectively).

\section{NBO and AIM analyses}

For conformations showing an $\mathrm{OH} \cdots \mathrm{F} \mathrm{IMHB}$, the charge transfer, estimated with $E_{n-v^{*}}^{(2)}$, from the fluorine lone pair to the hydroxyl antibonding orbital was calculated through NBO analyses (Table 1). This electronic descriptor is found to be well-correlated to the structural parameter $\mathrm{d}_{\mathrm{OH}} \ldots \mathrm{F}$, with the strongest charge transfers corresponding to the shortest distances. Furthermore, in general the charge transfer decreases from the monofluorinated to the trifluorinated derivatives (typically from 4 to 3 , and to $2 \mathrm{~kJ} \mathrm{~mol}^{-1}$ ), in line with their decreasing $\mathrm{H}$-bond accepting character. ${ }^{[3 \mathrm{u}]}$

AIM analysis ${ }^{[18]}$ may lead to the localization of a bond critical point (BCP) between the fluorine and the hydroxyl hydrogen atoms. From the potential energy densities $V_{b}$ computed at the $\mathrm{BCP}$, the energy $\left(E_{\mathrm{HB}}\right)$ of the corresponding IMHB interaction can be estimated. ${ }^{[3 \mathrm{~h},} 3 \mathrm{i},{ }^{12]}$ Unfortunately, these analyses systematically failed to find any BCP in the $\beta$-fluorohydrin series, which is in agreement with literature reports of similar 5membered IMHB motifs. ${ }^{[19]}$

\section{Theoretical $\mathrm{H}$-bond acidity estimation}

The $\mathrm{H}$-bond acidity is a property that can be estimated from the calculation of the electrostatic potential parameter $V_{a}(r){ }^{[6 c, 7]}$ For a given compound, the individual values are first computed for each conformer detected on the potential energy surface (see Supporting Information), a weighted $V_{a}(r)$ value being then derived from the Boltzmann distribution (Table 1). Regardless the series, the highest $V_{a}(r)$ values are computed for the trifluorinated alcohols, followed systematically by the difluorinated ones, and finally the monofluorinated derivatives. As already depicted and rationalized for other fluorohydrin derivatives, ${ }^{[3], 7]}$ it is worth noting that the values calculated for non-fluorinated compounds are located between the mono- and the difluoroalcohols (except in series $\mathbf{5}$, see Table S7).

\section{H-bond acidity measurements}

The $\mathrm{H}$-bond donating capacity, $\mathrm{p} K_{\mathrm{AHY}}$, of the alcohols is determined by IR spectroscopy through complexation with a standard $\mathrm{H}$-bond acceptor, $\mathrm{N}$-methylpyrrolidinone (NMP), in $\mathrm{CCl}_{4}$ at $25^{\circ} \mathrm{C}$ as shown in Figure $1 .{ }^{[6 \mathrm{c}]}$ The decrease in intensity of the $v_{\mathrm{OH}}$ band with increasing amounts of NMP is measured, as well as the frequency shifts, $\Delta v_{\mathrm{OH}}$, of the $\mathrm{OH}$ band observed upon complexation. The measured $\Delta v_{\mathrm{OH}}, \varepsilon_{\mathrm{OH}}, \mathrm{p} K_{\mathrm{AHY}}$ values, and the corresponding free energies of complexation, $\Delta G_{\mathrm{AHY}}$, are gathered in Table 2. The intensity of the $\mathrm{v}_{\mathrm{OH}}$ stretching vibration significantly increases upon fluorination. The molar absorption coefficient, $\varepsilon_{\mathrm{OH}}$, in difluorinated derivatives reaches twice the unfluorinated values, while a limited increase is finally measured with a third fluorination.

To facilitate discussion of the various trends, the $\mathrm{p} K_{\mathrm{AHY}}$ values of 3-6 are also presented on an experimental scale in Figure 3. A striking result is the opposite variation of $\mathrm{H}$-bond acidity observed upon the first fluorination according to the chemical structure of the fluorinated derivatives. Whereas compounds $\mathbf{3 b}$ and $\mathbf{4 b}$ are significantly less acidic than their non-fluorinated analogues $3 \mathrm{a}$ and $\mathbf{4 a}, \mathbf{3 c}$ shows a $\mathrm{H}$-bond acidity almost equivalent to $3 a$. Moreover, an increase in $\mathrm{p} K_{\mathrm{AHY}}$ value is measured for compounds $\mathbf{5 b}$ and $\mathbf{6} \mathbf{b}$, by comparison with $\mathbf{5 a}$ and 6a. The difference between closely related stereoisomers such as $\mathbf{3 b} / \mathbf{3 c}$, and $\mathbf{4 b} / \mathbf{5 b}$ is unexpected.

Irrespective of the series under study, difluorination and trifluorination lead to significant and similar enhancements of $\mathrm{H}$ bond acidity. At equivalent fluorination state, the $\mathrm{H}$-bond acidity

Table 2. Experimental spectroscopic features, $v_{\mathrm{OH}}, \varepsilon_{\mathrm{OH}}$, and $\Delta v_{\mathrm{OH}}$, and $\mathrm{H}$-bond acidity properties, $\mathrm{p} K_{\mathrm{AHY}}, \Delta \mathrm{G}_{\mathrm{AHY}}$, of $\beta$-fluorohydrins under study.

\begin{tabular}{|c|c|c|c|c|c|c|}
\hline Entry & $v_{\mathrm{OH}}{ }^{[a]}$ & $\varepsilon_{\mathrm{OH}}^{[b]}$ & $v_{\mathrm{OH}} \ldots{ }^{[a]}$ & $\Delta v_{\mathrm{OH}}{ }^{[a]}$ & $\mathrm{p} K_{\mathrm{AHY}}$ & $\Delta G_{A H Y}$ \\
\hline $3 a^{[d]}$ & 3623 & 64 & 3449 & 174 & 0.67 & -3.8 \\
\hline $3 b$ & 3608 & 103 & 3414 & 194 & 0.47 & -2.7 \\
\hline $3 c$ & 3615 & 127 & 3416 & 199 & 0.66 & -3.8 \\
\hline $3 d$ & 3617 & 129 & 3382 & 235 & 0.98 & -5.6 \\
\hline $4 a$ & 3616 & 61 & 3452 & 164 & 0.63 & -3.6 \\
\hline $4 b$ & 3603 & 120 & 3417 & 186 & 0.51 & -2.9 \\
\hline $4 c$ & 3602 & 136 & 3378 & 224 & 0.85 & -4.9 \\
\hline $4 d$ & 3602 & 139 & 3345 & 257 & 1.28 & -7.3 \\
\hline $5 a$ & 3612 & 79 & 3443 & 169 & 0.55 & -3.1 \\
\hline $5 b$ & 3606 & 111 & 3412 & 194 & 0.76 & -4.3 \\
\hline $5 c$ & 3605 & 119 & 3378 & 227 & 1.06 & -6.0 \\
\hline $5 d$ & 3604 & 140 & 3344 & 260 & 1.48 & -8.4 \\
\hline $6 a$ & 3628 & 54 & 3452 & 176 & 0.72 & -4.1 \\
\hline $6 b$ & 3617 & 60 & 3414 & 202 & 0.81 & -4.6 \\
\hline $6 c$ & 3619 & 92 & 3367 & 252 & 1.24 & -7.1 \\
\hline $6 d$ & 3620 & 93 & 3335 & 285 & 167 & -95 \\
\hline
\end{tabular}

[a] $\mathrm{cm}^{-1},[\mathrm{~b}] \mathrm{L} \mathrm{mol}^{-1} \mathrm{~cm}^{-1},[\mathrm{c}] \mathrm{kJ} \mathrm{mol}^{-1}$, [d] ref ${ }^{[6 \mathrm{c}]}$.

is roughly found to be stronger when the $\beta$-fluorohydrin $C-C$ bond presents an increasing degree of conformational flexibility.

\section{Discussion: influence of fluorination on $\mathrm{p} K_{\mathrm{AHY}}$}

The experimental observations are explained through a careful analysis of the conformational profile of the compounds. For $\mathbf{3 b}$, each chair conformer allows for OH $\cdots$ F IMHB (95\% of the total population), while the trans isomer $3 \mathbf{c}$ exhibits only one conformation featuring an $\mathrm{OH} \cdots \mathrm{F}$ IMHB $(88 \%$ of the total population), next to conformations featuring a trans-diaxial fluorohydrin motif, or a trans-diequatorial fluorohydrin motif with the $\mathrm{OH}$ bond rotated away from the fluorine (no OH $\cdots$ F IMHB). 

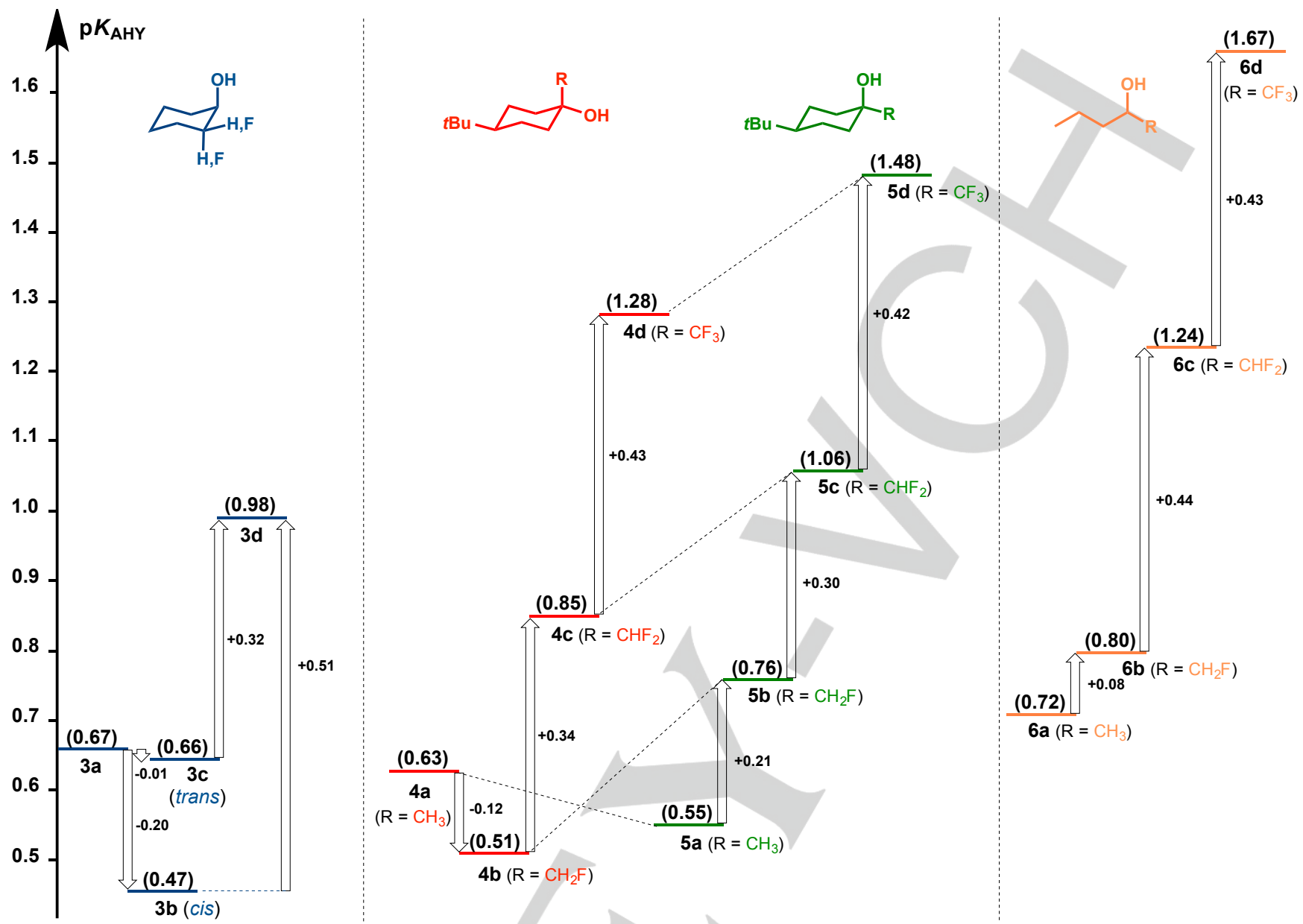

Figure 3. Experimental $\mathrm{H}$-bond acidity variations observed for series 3-6 upon an increasing degree of fluorination.

Hence, the dependence of the measured $\mathrm{p} K_{\mathrm{AHY}}$ values for the monofluorinated cyclohexanols on their relative stereochemistry can be explained as follows: in $\mathbf{3 b}$, the $\mathrm{OH} \cdots \mathrm{F}$ IMHB in both conformers leads to a decrease of the $\mathrm{H}$-bond acidity.

Conversely for $\mathbf{3 c}$, conformations leading to its increase are significantly populated $(12 \%)$, enough to compensate for the attenuating effect of the $\mathrm{OH} \cdots \mathrm{F} I \mathrm{MHB}$, leading to an overall negligible change in $\mathrm{pK}_{\mathrm{AHY}}$ compared to $\mathbf{3 a}$. It is interesting to compare how the different conformations without any IMHB contribute to the overall $\mathrm{p} K_{\mathrm{AHY}}$ value. For the trans-diaxial $A x \_g$, an increase of $\mathrm{p} K_{\mathrm{AHY}}$ of +0.72 is calculated from the individual electrostatic potential values (see Section 3 in $\mathrm{SI}$ ), which is in line with the +0.59 increase experimentally observed between compounds $\mathbf{2 a}$ and $\mathbf{2 b}$. In contrast, a weaker increase $(+0.41)$ is calculated for the non IMHB trans-diequatorial forms, which is consistent with the aforementioned dependence of the fluorine inductive effect on the dihedral angle..$^{[7]}$

There is an internal consistency between the $\mathrm{H}$-bond properties of $3 b / 3 c$ and those of the corresponding conformationally rigid fluorohydrins $\mathbf{1 b} / \mathbf{1 c}$ and $\mathbf{2 c / 2 b}$. The hydroxyl surroundings of the axial and equatorial conformations of $\mathbf{3 b}$ are equivalent to that of compounds $\mathbf{2 c}$ and $\mathbf{1 b}$, respectively. Hence, similar $\mathrm{OH} \cdots \mathrm{F}$ IMHBs to that of compounds 2c and $\mathbf{1 b}$ are observed, with $\mathrm{OH} \cdots \mathrm{F}$ distances shorter than 2.3 $\AA$. Moreover, the charge transfer from the fluorine lone pair to the $\mathrm{O}-\mathrm{H}$ antibonding orbital is in each case slightly larger than 4 $\mathrm{kJ} \mathrm{mol}{ }^{-1}$. Similarly, the decrease of $\mathrm{H}$-bond donating ability observed for $3 \mathbf{b}$ ( $0.20 \mathrm{pK}$ units) from the non-fluorinated counterpart $\mathbf{3 a}$ is very similar to that observed from $\mathbf{2 a}$ to $\mathbf{2 c}$, and from $1 \mathrm{a}$ to $\mathbf{1 b}$ (Figure 1). Interestingly, the $\mathrm{H}$-bond acidity of the cis fluorohydrin $\mathbf{3 b}$ is very nicely estimated from the experimental $\mathrm{p} K_{\mathrm{AHY}}$ values of $\mathbf{1 c}$ and $\mathbf{2 b}$ weighted by the corresponding computed equatorial and axial populations of $\mathbf{3 b}$ (Scheme 1(a) and Table S1). For the IMHB conformer of $\mathbf{3 c}$, the $\mathrm{OH} \cdots \mathrm{F}$ distance is longer $(2.370 \AA)$ and the charge transfer is weaker $\left(3.20 \mathrm{~kJ} \mathrm{~mol}^{-1}\right)$ than found in $\mathbf{3 b}$, but exactly as found in the equivalent derivative $1 \mathrm{c}$. Again, the $\mathrm{p} K_{\mathrm{AHY}}$ value for $3 \mathrm{c}$ can be derived from the corresponding weighted values of $\mathbf{1 c}$ and $\mathbf{2 b}$ (Scheme 1(a)).

Difluorination (3d) significantly enhances the H-bond acidity despite the possibility to form $\mathrm{OH} \cdots \mathrm{F}$ IMHBs irrespective of the hydroxyl position (axial/equatorial). In these systems, the fluorine electron withdrawing effect prevails over the IMHB effect, a behavior previously observed with the rigid substrates $\mathbf{1 d}$ and 2d (Figure 1). As shown in Scheme 1(b), there is again an excellent equivalence between the experimental $\mathrm{H}$-bond acidity 
of the flexible difluorinated alcohol $\mathbf{3 d}$ and the value estimated from the combination of the rigid compounds $\mathbf{1} \mathbf{d}$ and $\mathbf{2 d}$.

Substrates $\mathbf{4}$ and $\mathbf{5}$, which feature full conformational flexibility around the $\mathrm{C}(\mathrm{OH})-\mathrm{C}\left(\mathrm{H}_{n} \mathrm{~F}_{3-n}\right)$ bond, are distinguished by the fixed equatorial and axial orientation of the alcohol group. For the two nonfluorinated alcohols $\mathbf{4 a}$ and $\mathbf{5 a}$, a slight decrease in $\mathrm{H}$-bond acidity is observed compared with the non-methylated analogues $\mathbf{1 a}$ and $\mathbf{2 a}$ (Figure 1). ${ }^{[7]}$ In addition, in contrast to $\mathbf{1 a}$ vs $\mathbf{2 a}$, the axial alcohol $\mathbf{5 a}$ has a lower $\mathrm{p} K_{\mathrm{AHY}}$ value compared to

(a)

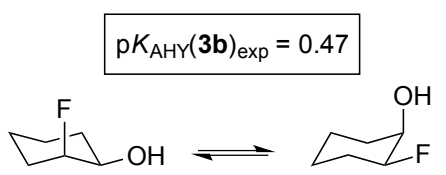

$$
\text { pK }
$$

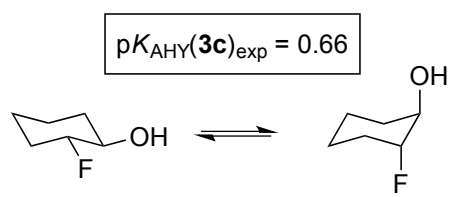

$$
\begin{aligned}
\mathrm{p} K_{\mathrm{AHY}}(\mathbf{3 c}) & =p_{i} \cdot \mathrm{p} K_{\mathrm{AHY}}(\mathbf{2 b})+\left(1-p_{i}\right) \cdot \mathrm{p} K_{\mathrm{AHY}}(\mathbf{1 c}) \\
& =0.93 \cdot 0.56+0.07 \cdot 1.30 \\
\mathrm{p} K_{\mathrm{AHY}}(\mathbf{3 c}) & =0.61
\end{aligned}
$$

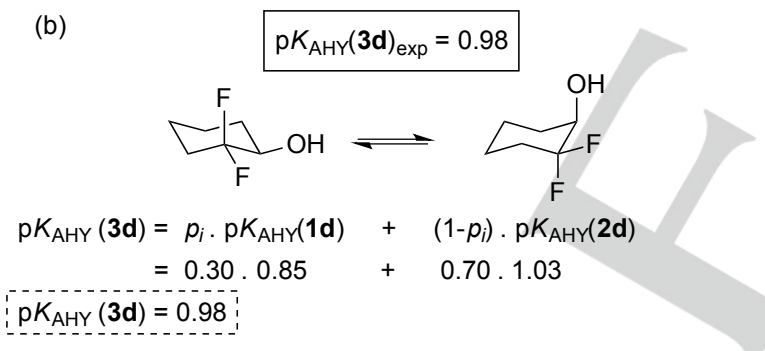

Scheme 1. Correlation between the experimental $\mathrm{p} K_{\mathrm{AHY}}$ values of $\mathbf{3 b}, \mathbf{3} \mathbf{c}$ and $\mathbf{3 d}$, and the values estimated by combination of the computed conformer distribution and the experimental $\mathrm{p} K_{\mathrm{AHY}}$ values of series 1 and $\mathbf{2}$.

the equatorial alcohol $\mathbf{4 a}$. The overall decrease can be explained by the electron-donating inductive effect of the methyl substituent on the hydroxyl group, possibly augmented by steric effects that can occur in these tertiary alcohols. The lower $\mathrm{p} K_{\mathrm{AHY}}$ value for the axial alcohol could be due to the electron donating $\sigma_{\mathrm{C}-\mathrm{H}} \rightarrow \sigma_{\mathrm{C}-\mathrm{O}}^{*}$ hyperconjugation. Indeed, the NBO analysis for isomer 5 a shows that three $\sigma_{\mathrm{C}-\mathrm{H}}$ bonding orbitals exhibit charge transfer to the $\sigma^{*}$ C-o antibonding orbital amounting from 20 to 25 $\mathrm{kJ} \mathrm{mol}^{-1}$. In contrast, only one $\sigma_{\mathrm{C}-\mathrm{H}}$ bonding orbital is involved in isomer $4 \mathrm{a}$, with a charge transfer of 18 to $21 \mathrm{~kJ} \mathrm{~mol}^{-1}$ (in addition to weaker ones due to $\sigma_{\mathrm{C}-\mathrm{c}} \rightarrow \sigma^{*} \mathrm{c}-\mathrm{o}$ hyperconjugation, from 12 to $14 \mathrm{~kJ} \mathrm{~mol}^{-1}$ ). As a result, calculated partial charges from the Natural Population Analysis, are slightly more negative on the oxygen and slightly less positive on the hydrogen atom of $\mathbf{5 a}$, in line with its experimental weaker $\mathrm{H}$-bond acidity.
Then, the behaviors within these two series are different upon fluorination of the methyl group. A decrease in $\mathrm{p} K_{\mathrm{AHY}}$ indeed occurs upon monofluorination for $\mathbf{4 b}$, while there is an increase for $\mathbf{5 b}$. This trend can also be rationalized by the conformational features of these derivatives. For $4 \mathbf{b}, 86 \%$ of the population is that of the $G \_g^{+}$conformation, which presents an IMHB motif, while the corresponding conformer for $\mathbf{5 b}$ has a notably lower population (72\%). Also, the IMHB in $\mathbf{4 b}$ is shorter compared to that in $\mathbf{5 b}$, resulting in a larger $n_{F} \rightarrow \sigma^{*}{ }_{O-H}$ charge transfer. Furthermore, $\mathbf{4} \mathbf{b}$ has a negligible population of conformers where the $\mathrm{C}-\mathrm{F}$ and $\mathrm{C}-\mathrm{OH}$ bonds are antiperiplanar $(3 \%)$, while 5 b features two such conformers totaling $25 \%$ in population.

For both $\mathbf{4}$ and $\mathbf{5}$ series, a similar increase is observed upon di- (+0.30 pK units) and trifluorination (+0.42 pK units), with the $\mathrm{H}$-bond donating ability of $\mathbf{5 b}$ - $\mathbf{d}$ thus being systematically higher than that of $\mathbf{4 b}$-d. Hence, $\mathbf{4 c}$ has a lower $\mathrm{p} K_{\mathrm{AHY}}$ value $(0.85)$ than 5c (1.06), despite both have a similar population of IMHB conformations $(90 \%$ vs $88 \%)$. However, for equivalent conformers the $\mathrm{OH} \cdots \mathrm{F}$ distance is larger in the latter, resulting in a smaller charge transfer. Hence, their IMHB is weaker, resulting in a larger $\mathrm{H}$-bond acidity. In addition, 5c exhibits a larger population where the $\mathrm{C}-\mathrm{F}$ and $\mathrm{C}-\mathrm{OH}$ bonds are antiperiplanar $(87 \%)$ compared to $4 \mathrm{c}(49 \%)$. The same explanation is invoked for the lower $\mathrm{p} K_{\mathrm{AHY}}$ value for $\mathbf{4 d}$ compared to $\mathbf{5 d}$ : despite the IMHB conformation for the former is less populated $(90 \%)$ than that of $\mathbf{5 d}(\mathbf{d} \%)$, the weaker IMHB for $\mathbf{5 d}$ compared to that of $\mathbf{4 d}$ is again taken as origin for the measured $\mathrm{H}$-bond acidity difference.

In the acyclic series $\mathbf{6}$, conformational analysis of $\mathbf{6 b}$ (Table S4) reveals that the features of the IMHB conformers, a population of $84 \%$ with a mean distance $(2.326 \AA)$ and a mean charge transfer $\left(3.8 \mathrm{~kJ} \mathrm{~mol}^{-1}\right)$, are intermediate between $\mathbf{4 b}$ and $\mathbf{5 b}$. This is in good agreement with the rather small increase upon monofluorination $\left(\Delta \mathrm{p} K_{\mathrm{AHY}}=+0.08\right)$ from $\mathbf{6 a}$ to $\mathbf{6 b}$, that can be compared to the significant decrease observed in series 4 and to the important increase found in series $\mathbf{5}$. Much stronger enhancements are measured with the introduction of a second $\left(\Delta \mathrm{p} K_{\mathrm{AHY}}=+0.44\right.$ from $6 \mathrm{~b}$ to $\left.6 \mathrm{c}\right)$ and a third fluorine atom $\left(\Delta \mathrm{p} K_{\mathrm{AHY}}\right.$ $=+0.43$ from $6 \mathrm{c}$ to $6 \mathrm{~d}$ ). Again, the mean intramolecular distance $(2.350 \AA)$ and charge transfer $\left(2.3 \mathrm{~kJ} \mathrm{~mol}^{-1}\right)$ found in $6 \mathrm{c}$ (Table S5) are less favorable than in $\mathbf{4 c}$ and $\mathbf{5 c}$, and in line with the greater increase of $\mathrm{p} K_{\mathrm{AHY}}$ observed from $4 \mathrm{~b} / \mathbf{5 b}$ to $4 \mathrm{c} / \mathbf{5 c}$.

All these data clearly illustrate the influence of fluorine on the hydroxyl $\mathrm{H}$-bond acidity. On the one hand, the major role is obviously played by the increased electron withdrawing effect with higher degree of fluorination yielding to $\mathrm{H}$-bond acidity increase. On the other hand, the occurrence of IMHB conformations acts against this increase, with a greater extent for monofluorinated compounds than for di- and trifluorinated derivatives, given to the reduced $\mathrm{H}$-bond accepting ability of the latter. ${ }^{[3 q]}$ Moreover, it is shown that, for a given degree of fluorination, very subtle differences, either in populations or strengths of such IMHB conformers, have a direct and observable impact on their H-bond acidity. 


\section{Frequency shifts upon complexation $\left(\Delta v_{\mathrm{OH}}\right)$}

During the experimental determination of the $\mathrm{H}$-bond acidity by IR spectroscopy, a systematic frequency shift of the hydroxyl stretching vibration, $\Delta v_{\mathrm{OH}}$, towards lower wavenumbers is consistently observed upon complexation with NMP. We have previously shown that $\Delta v_{\mathrm{OH}}$ is correlated to $\mathrm{p} K_{\mathrm{AHY}}$ for homogeneous families of compounds (Figure 4A). $\left.{ }^{3 \mathrm{~h},}{ }^{6 \mathrm{c}}\right]$ Accordingly, for $1-6, \Delta v_{\mathrm{OH}}$ is dependent on the number of fluorine atoms. The following frequency shift ranges are measured: $170 \pm 10 \mathrm{~cm}^{-1}$ for the unfluorinated, $190 \pm 10 \mathrm{~cm}^{-1}$ for the monofluorinated, $230 \pm 10 \mathrm{~cm}^{-1}$ for the difluorinated, and finally $260 \pm 10 \mathrm{~cm}^{-1}$ for the trifluorinated cyclohexanols.

We have also shown that deviations from the $\mathrm{p} K_{\mathrm{AHY}}-\Delta v_{\mathrm{OH}}$ correlation can reveal peculiar behaviors, such as IMHBs. ${ }^{[3 \mathrm{~h}, 6 \mathrm{cc}]}$ This is consistent with the significant downward deviation that can be found for fluorohydrins 1-4 (Figure 4B), the compounds belonging to series 5 and 6 being situated within the standard
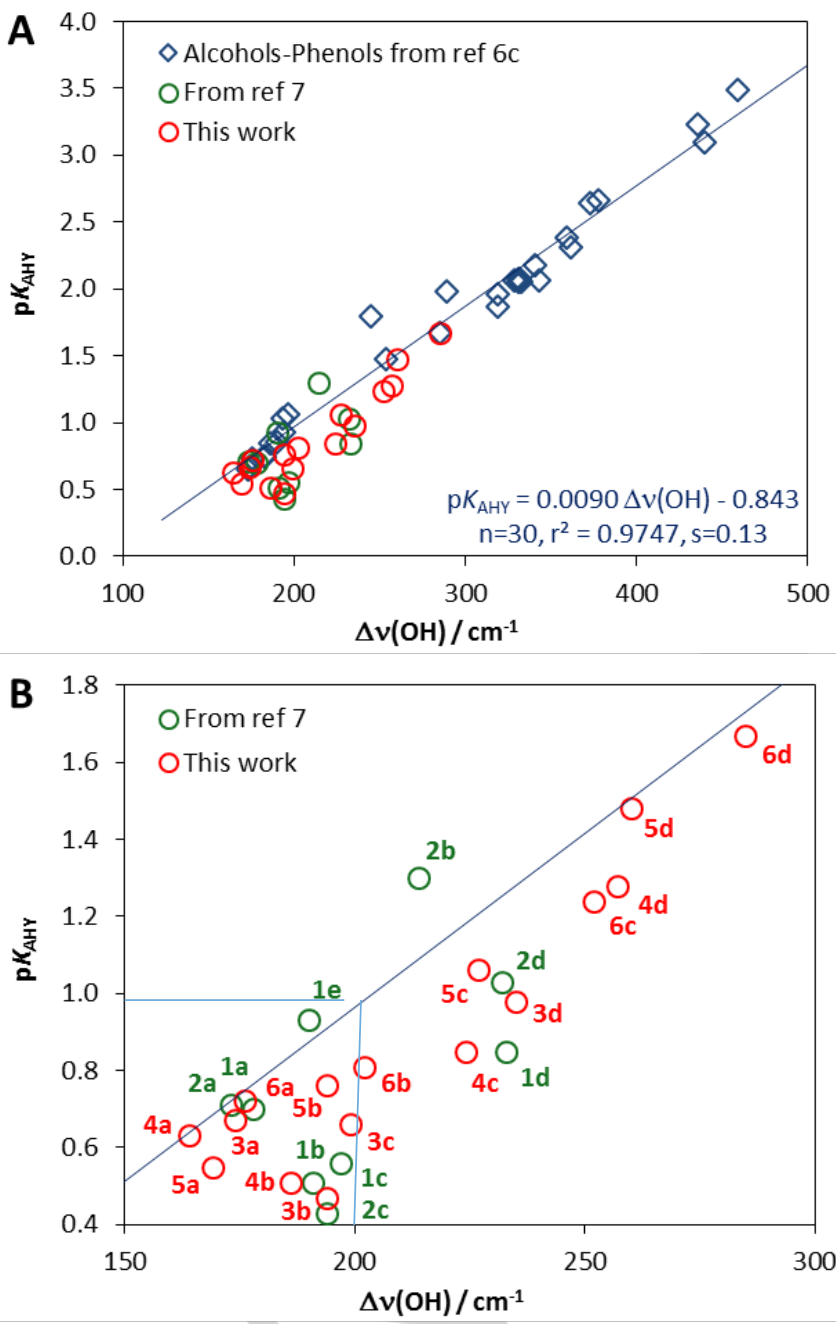

Figure 4. Plot of $\mathrm{p} K_{\mathrm{AHY}}$ versus $\Delta v_{\mathrm{OH}}$ frequency shift for a series of alcohols and phenols (A) and extension (B) to emphasize the downward deviations observed for fluorohydrins (ref. ${ }^{[7]}$ and this work) with IMHB conformations in $\mathrm{CCl}_{4}$. deviation of this calibration line ( 0.13 units). This behaviour is attributed to the occurrence of $\mathrm{OH} \cdots \mathrm{F}$ IMHB interactions. In series 4 , the higher deviations from the $\mathrm{p} K_{\mathrm{AHY}}-\Delta v_{\mathrm{OH}}$ correlation, at equivalent fluorination states than in series $\mathbf{5}$, are caused by stronger IMHBs as highlighted by our conformational analysis.

With equivalent fluorination states, $\mathbf{3 b}$ and $\mathbf{3 c}$ show equivalent $\Delta v_{\mathrm{OH}}$ values but the deviation from the regression line is much less pronounced for $\mathbf{3 c}$. This is rationalized by the occurrence of an $\mathrm{OH} \cdots \mathrm{F}$ IMHB interaction only in the equatorial conformer of $\mathbf{3 c}$, whereas both axial and equatorial forms can exhibit such an IMHB in $\mathbf{3 b}$. The deviation observed for $\mathbf{3 d}$ is also less important than for $\mathbf{3 b}$. It can be attributed to the compensation of the fluorine electron-withdrawing effect that increases the frequency shift, towards the occurrence of IMHBs, weakened for a $\mathrm{CF}_{2}$ group in comparison with a CF one. ${ }^{[3 \mathrm{u}]}$ The same behavior is apparent for the trifluorinated derivatives $\mathbf{4 d}$, $\mathbf{5 d}$ and $\mathbf{6 d}$, where the $\mathrm{H}$-bond accepting ability of $\mathrm{CF}_{3}$ is even worse. ${ }^{[3 u]}$

The two experimental parameters $\mathrm{p} K_{\mathrm{AHY}}$ and $\Delta v_{\mathrm{OH}}$ measure two different features of the hydrogen-bond. The logarithm of the equilibrium constant, $\mathrm{p} K_{\mathrm{AHY}}$, is a thermodynamic parameter and takes into account the intrinsic properties of both the fluorohydrin monomer and of its $\mathrm{H}$-bond complex with NMP. As a consequence, when an IMHB involving the $\mathrm{H}$-bond donor moiety of the monomer can occur, it partially prevents the intermolecular $\mathrm{H}$-bond to be established with NMP. This results in a significant lowering of the equilibrium constant. Conversely, the frequency shift, $\Delta v_{\mathrm{OH}}$, is a spectroscopic probe comparing the stretching frequencies before and after $\mathrm{H}$-bond complexation without considering any equilibrium aspects. It is mainly dependent of the intermolecular $\mathrm{H}$-bond complex because, as can be seen in Table 2, the monomeric $\mathrm{v}_{\mathrm{OH}}$ stretching mode is just slightly disturbed by the weak $\mathrm{OH} \cdots \mathrm{F}$ IMHB. As a consequence, $\Delta v_{\mathrm{OH}}$ is much less influenced by IMHB than $p K_{\mathrm{AHY}}$, and this results in downward deviations from the $\mathrm{p} K_{\mathrm{AHY}}-\Delta v_{\mathrm{OH}}$ correlation. As an example, by considering $3 \mathbf{c}$ and the corresponding experimental $\Delta v_{\mathrm{OH}}$ of $199 \mathrm{~cm}^{-1}$, it can be seen from the correlation of Figure $4 \mathrm{~B}$ that such $\Delta v_{\mathrm{OH}}$ should lead to a $\mathrm{p} K_{\mathrm{AHY}}$ value close to 0.95 , whereas the observed $\mathrm{pK}$ value is 0.66 , illustrating the direction (downward) of the observed deviations.

\section{Experimental vs theoretical $\mathrm{H}$-bond acidity.}

The comparison between the experimental $\mathrm{p} K_{\mathrm{AHY}}$ values and the theoretical $V_{a}(r)$ descriptor of $\mathrm{H}$-bond acidity is very instructive. On the whole, there is an excellent correlation between the experimentally determined and the calculated $\mathrm{p} K_{\mathrm{AHY}}$ values, even for closely related stereoisomers with significantly different $\mathrm{H}$-bond acidities.

For series 3, a clear decrease in $\mathrm{H}$-bond acidity is indeed predicted upon cis-monofluorination, and a much lower decrease upon trans-monofluorination (Table 1). The significant increase upon addition of a second fluorine atom (3d) was correctly predicted. In series $\mathbf{4}$, we observe at first a decrease of $V_{\text {c }}(r)$ upon fluorination (Table 1), and then an increase with diand trifluorination. The regular increase of $V_{a}(r)$ calculated for series 5 is in agreement with the experimental trend. The 
systematic higher $\mathrm{H}$-bond acidity properties of $\mathbf{5 b}, \mathbf{5} \mathbf{c}$ and $\mathbf{5 d}$, in comparison with $\mathbf{4 b}, \mathbf{4 c}$ and $\mathbf{4 d}$, is also well reproduced.

Within series 6 , the electrostatic potential descriptor fails describing the increase of the $\mathrm{H}$-bond acidity due to the first fluorination. The contribution of the IMHB seems to be overestimated, resulting in a too strong attenuation of the predicted $\mathrm{p} \mathrm{K}_{\mathrm{AHY}}$ value. However, the computed values for the diand trifluoropentanols are in good agreement with the experimental data, corroborating that with a higher conformational flexibility, the fluorine inductive effect overrides the IMHB contribution.

Hence, with one exception, this clearly demonstrates the validity of the Kenny electrostatic descriptor $V_{a}(r)$ in probing the hydrogen bond donating capacity of fluorohydrins, the effects of fluorination being well-reflected. An excellent correlation between $\mathrm{pK}_{\mathrm{AHY}}$ and $V_{\mathrm{a}}(\mathrm{r})$ for all hydroxyl H-bond donors studied so far (78 compounds), ${ }^{[3 \mathrm{~h}, 3 \mathrm{j}, 6 \mathrm{c}, 7]}$ including the current series of 15 alcohols, is shown in Figure 5. The resulting sample yields a robust correlation equation, Eq.(1), which updates the previously reported calibration line. ${ }^{[6]}$ The corresponding predicted values for the current series are given in Table S7, for comparison with experimental data.

$$
\begin{aligned}
\mathrm{p} K_{\mathrm{AHY}} & =50.14 V_{\mathrm{c}}(\mathrm{r})-15.26 \\
\mathrm{n} & =78, \mathrm{r}^{2}=0.9731, \mathrm{~s}=0.116, \mathrm{~F}=2749
\end{aligned}
$$

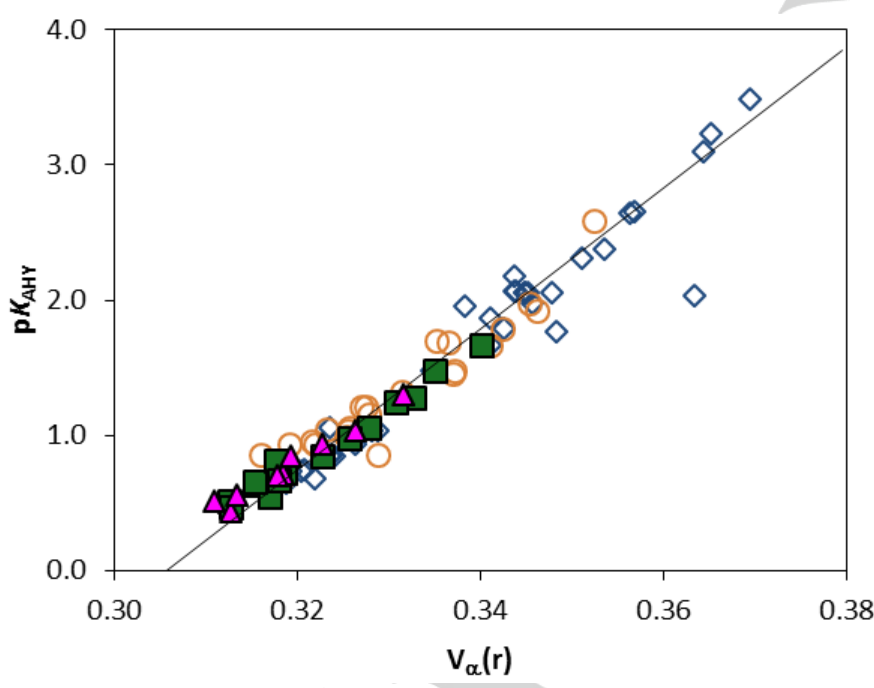

Figure 5. Plot of $\mathrm{p} K_{\mathrm{AHY}}$ versus the $V_{\mathrm{a}}(\mathrm{r})$ electrostatic potential descriptor. The fluorohydrins studied in the current work (in green squares, see numerical values in Table S7) obey to the correlation previously established. The rigid fluorohydrins $^{[7]}$ are also highlighted in pink triangles, alcohols and phenols ${ }^{[6 c]}$ are shown in blue diamond and benzyl alcohols ${ }^{[3 h]}$ in orange circles. The calibration equation is hence updated with this dataset of 78 compounds.

\section{Conclusion}

The $\mathrm{H}$-bond donating capacities of four series of aliphatic $\beta$ fluorohydrins, characterized by increasing conformational flexibility, have been investigated by FTIR measurements and quantum chemical calculations. It was found that the $\mathrm{H}$-bond acidity $\left(p K_{\mathrm{AHY}}\right)$ of $\beta$-monofluorinated alcohols was either lower, similar, or higher compared to the nonfluorinated parent, Beyond these general observations, with unexpected differences between closely related diastereomers, either within a series (eg 3), or between series (4 and 5). In contrast, geminal di- and trifluorination always led to successive $\mathrm{p} K_{\mathrm{AHY}}$ increases.

The observations were rationalized through considering two main effects: the fluorine electronegativity (leading to an increase in $\mathrm{H}$-bond acidity), and intramolecular hydrogen bonding between the fluorine and the alcohol group (leading to a decrease). The extent of intramolecular hydrogen bonding for flexible fluorohydrins was determined by conformational analysis. Between diastereomeric substrates, it was found that the relative population of IMHB conformers, as well as the calculated $\mathrm{OH} \cdots \mathrm{F}$ distance (which was correlated with the charge transfer occurring within the IMHB) could explain differences in $\mathrm{H}$-bond donating capacity. For example, 2-cis-fluorocyclohexanol $\mathbf{3 b}$ has a lower $\mathrm{H}$-bond acidity, and 2-trans-fluorocyclohexanol 3c a similar H-bond acidity as cyclohexanol. Indeed, in the former, the two chair conformations of the cyclohexyl ring can lead to the formation of an $\mathrm{OH} \cdots \mathrm{F} I \mathrm{IMHB}$, whereas only one chair conformation can give an $\mathrm{OH} \cdots \mathrm{F}$ interaction in $3 \mathrm{c}$, while its other chair conformation has a vicinal trans fluorohydrin motif, which is known to increase the $p K_{\mathrm{AHY}}$. Hence, in 3c, these opposite effects cancel each other, resulting in $3 \mathrm{c}$ having a similar $\mathrm{H}$ bond acidity compared to cyclohexanol. It was also evidenced that there is an internal consistency between the $\mathrm{p} K_{\mathrm{AHY}}$ values of conformationally rigid, fluorinated cyclohexanols, and the individual 2-fluoro and 2,2-difluorocyclohexanol chair conformations.

The examination of the relation between the two experimental parameters, $\mathrm{p} K_{\mathrm{AHY}}$ and $\Delta v_{\mathrm{OH}}$, provides useful complementary information. Since the two parameters measure different features of the $\mathrm{H}$-bond interaction, deviations from the relation reveals peculiar behaviors. Indeed, the significant downward deviations observed in the $\mathrm{p} K_{\mathrm{AHY}} \mathrm{vs} \Delta \mathrm{v}_{\mathrm{OH}}$ are attributed to the occurrence of IMHB with subtle differences, these experimental findings being well corroborated by the results of the theoretical conformational analysis.

It was confirmed that the Kenny theoretical $V_{a}(r)$ descriptor of $\mathrm{H}$-bond acidity accurately reflects these effects (one exception). An updated correlation between the experimental $\mathrm{p} K_{\mathrm{AHY}}$ and $V_{a}(r)$ descriptor values of 78 fluorinated and nonfluorinated alcohol $\mathrm{H}$-bond donors is presented.

Hence, apart from the fluorine electron withdrawing effect, our results clearly show that $\mathrm{OH} \cdots \mathrm{F}$ IMHB is a determining factor in the $\mathrm{H}$-bond donating capacity of fluorohydrins. Variations in population of IMHB conformers and subtle differences in IMHB strengths were shown to correlate with the $\mathrm{p} K_{\mathrm{AHY}}$ value. The demonstration that our updated correlation equation accurately predicts fluorohydrin $\mathrm{H}$-bond donating capacity from the calculated Kenny $V_{a}(r)$ descriptor for both conformationally rigid and flexible fluorohydrins, will be of general interest in the many research fields for which intermolecular hydrogen bonding and its modulation by fluorination is of interest. A significant consequence of this work 
regards the possibility to obtain accurate $\mathrm{H}$-bond donating capacity data for fluorohydrins that are part of more complex, polyfunctional substrates, as experimental determination would not be possible for such substrates.

\section{Experimental Section}

Fluorohydrins synthesis. The details of the synthesis of substrates $3 \mathbf{b}$ d, 4a-d, 5a-d, 6b-d (Figure 1) is given in the Supporting Information (SI).

Chemicals. Carbon tetrachloride solvent, of spectroscopic grade, was kept for several days over freshly activated $4 \AA$ molecular sieves before use. Commercial $\mathrm{N}$-methylpyrrolidinone, $99.5+\%$ of purity, was also stored over molecular sieves and in darkness to prevent its deterioration. All cyclohexanol derivatives prepared for this study were solids, and therefore their ultimate purification and drying was carried out by sublimation in presence of $\mathrm{P}_{2} \mathrm{O}_{5}$. After control of its $\mathrm{GC}$ purity, the 1,1,1trifluoropentan-2-ol derivative, which is a liquid compound, was dried over freshly activated $4 \AA$ molecular sieves before use. Residual amount of $\mathrm{Et}_{2} \mathrm{O}$ and $\mathrm{CH}_{2} \mathrm{Cl}_{2}$ solvent have been detected for 1-fluoropentan-2-ol and 1,1-difluoropentan-2-ol and a transfer under high vacuum has been carried out prior to their drying.

FTIR Spectrometry measurements. The handling of all chemicals and their $\mathrm{CCl}_{4}$ solutions, and the filling of the cells for IR measurements were performed in the dry atmosphere of a glove box at room temperature. IR spectra were recorded in carbon tetrachloride solutions with a Fouriertransform spectrometer Bruker Vertex 70 at a resolution of $1 \mathrm{~cm}^{-1}$. An Infrasil quartz cell, of $\ell=1 \mathrm{~cm}$ path length and thermostatted at $25.0 \pm$ $0.2{ }^{\circ} \mathrm{C}$ by a Peltier effect regulation, was used for the studies of $\mathrm{H}$-bond complexation. The $\mathrm{H}$-bond acidity, $\mathrm{p} K_{\mathrm{AHY}}$, of the alcohols under study were measured as previously described ${ }^{[6 \mathrm{c}]}$ The stretching vibration $\mathrm{v}_{\mathrm{OH}}$, the molar absorption coefficients, $\varepsilon_{\mathrm{OH}}$, required for the equilibrium constant measurements, the frequency shift upon $\mathrm{H}$-bond complexation with $\mathrm{N}$-methylpyrrolidinone $\Delta v_{\mathrm{OH}}$ were determined for the synthesized compounds and are reported in Table 2. No fluorohydrin self-association was observed at the concentration employed.

\section{Computational procedure}

All DFT calculations were performed using the D. 01 version of the Gaussian 09 program. ${ }^{[20]}$ The conformational analysis of compounds under study was carried out with the MPWB1K functional ${ }^{[21]}$ and the 6$31+G(d, p)$ basis set. The solvent effects $\left(\mathrm{CCl}_{4}\right.$ herein) were introduced via the integral equation formalism of the polarizable continuum model (IEFPCM), and using the UFF cavity model. ${ }^{[22]}$ The vibrational spectrum was computed to check the nature of each optimized structures and to obtain free energies. The relative populations $p_{i}$ of the various conformers were hence evaluated from the computed free energies through a Boltzmann distribution (2). The theoretical descriptors were weighted according to these populations.

$$
p_{i}=\frac{e^{-\Delta G_{i} / R T}}{\sum_{i=1}^{n} e^{-\Delta G_{i} / R T}}
$$

The charge transfer between the acceptor lone pair(s) of electrons and the $\sigma^{*}$ donor antibonding orbital was estimated through NBO analyse ${ }^{[11]}$ to characterize the IMHB conformers. The corresponding interaction energies $\left(E_{n-\omega^{*}}^{(2)}\right)$ were evaluated from the second-order perturbation theory. The NBO analyses were applied at the IEF-PCM/MPWB1K/6$31+G(d, p)$ level of theory using the NBO6.0 program. ${ }^{[23]}$

The $\mathrm{H}$-bond acidity of the compounds under study were evaluated as recommended previously ${ }^{[6]]}$ through the calculation of the Kenny $V_{a}(r)$ descriptor. ${ }^{[8]}$ It consists in calculating in vacuo the electrostatic potential value along the $\mathrm{OH}$ bond at a distance $r=0.55 \AA$ from the hydroxyl hydrogen atom, at the MPWB1K/6-31+G(d,p) level of theory. Indeed, the initial data sets ${ }^{[6 \mathrm{c}, 7]}$ were considered in the gas phase at the MPWB1K/6$31+G(d, p)$ level of theory. The $V_{c}(r)$ value is determined for each conformation, taking into account the solvated geometry and a weighted value calculated from their respective Boltzmann populations.

\section{Acknowledgements}

The EPSRC (grants EP/K016938/1 and EP/K039466/1 (core capability)), and the ANR (JCJC "ProOFE" grant (ANR-13-JS080007-01), are gratefully acknowledged for their financial support. The current work was granted access to the HPC resources of (CCRT/CINES/IDRIS) under the allocation c2015085117 made by $\mathrm{GENCl}$, and HPC resources from ArronaxPlus, grant ANR$11-E Q P X-0004$ funded by the ANR. We thank the CCIPL for grants of computer time. Apollo Scientific is gratefully acknowledged for the donation of chemicals.

Keywords: H-bond acidity • Alcohols • Fluorination • FTIR spectroscopy $\cdot$ Quantum chemistry calculations

[1] D. O'Hagan, Chem. Soc. Rev. 2008, 37, 308-319.

[2] K. Muller, C. Faeh, F. Diederich, Science 2007, 317, 1881-1886.

[3] a) G. N. Manjunatha Reddy, M. V. Vasantha Kumar, T. N. Guru Row, N. Suryaprakash, Phys. Chem. Chem. Phys. 2010, 12, 13232-13237; b) C. Dalvit, A. Vulpetti, ChemMedChem 2012, 7, 262-272; c) G. T. Giuffredi, V. Gouverneur, B. Bernet, Angew. Chem., Int. Ed. 2013, 52, 1052410528; d) N. Martin-Pintado, M. Yahyaee-Anzahaee, G. F. Deleavey, G. Portella, M. Orozco, M. J. Damha, C. Gonzalez, J. Am. Chem. Soc. 2013, 135, 5344-5347; e) I. N'Go, S. Golten, A. Arda, J. Canada, J. Jimenez-Barbero, B. Linclau, S. P. Vincent, Chem. Eur. J. 2014, 20 , 106-112; f) B. Dugovic, C. J. Leumann, J. Org. Chem. 2014, 79, 12711279; g) S. K. Mishra, N. Suryaprakash, RSC Advances 2015, 5, 86013-86022; h) E. Bogdan, G. Compain, L. Mtashobya, J.-Y. Le Questel, F. Besseau, N. Galland, B. Linclau, J. Graton, Chem. Eur. J. 2015, 21, 11462-11474; i) B. Linclau, F. Peron, E. Bogdan, N. Wells, Z. Wang, G. Compain, C. Q. Fontenelle, N. Galland, J.-Y. Le Questel, J. Graton, Chem. Eur. J. 2015, 21, 17808-17816; j) E. Bogdan, A. Quarre de Verneuil, F. Besseau, G. Compain, B. Linclau, J.-Y. Le Questel, J. Graton, ChemPhysChem 2016, 17, 2702-2709; k) C. Ouvrard, M. Berthelot, C. Laurence, J. Chem. Soc., Perkin Trans. 2 1999, $1357-$ 1362; I) C. Ouvrard, M. Berthelot, C. Laurence, J. Phys. Org. Chem. 2001, 14, 804-810; m) W. Adcock, J. Graton, C. Laurence, M. Lucon, N. Trout, J. Phys. Org. Chem. 2005, 18, 227-234; n) C. Laurence, K. A. Brameld, J. Graton, J.-Y. Le Questel, E. Renault, J. Med. Chem. 2009, 52, 4073-4086; o) V. K. Batra, L. C. Pedersen, W. A. Beard, S. H. Wilson, B. A. Kashemirov, T. G. Upton, M. F. Goodman, C. E. McKenna, J. Am. Chem. Soc. 2010, 132, 7617-7625; p) C. Laurence, J. 
Graton, M. Berthelot, F. Besseau, J.-Y. Le Questel, M. Lucon, C. Ouvrard, A. Planchat, E. Renault, J. Org. Chem. 2010, 75, 4105-4123; q) C. Dalvit, A. Vulpetti, ChemMedChem 2011, 6, 104-114; r) C. Dalvit, A. Vulpetti, Chem. Eur. J. 2016, 22, 7592-7601; s) I. Hyla-Kryspin, G. Haufe, S. Grimme, Chem. Phys. 2008, 346, 224-236; t) B. Bernet, A. Vasella, Helv. Chim. Acta 2007, 90, 1874-1888; u) C. Dalvit, C Invernizzi, A. Vulpetti, Chem. Eur. J. 2014, 20, 11058-11068; v) M. Heger, T. Scharge, M. A. Suhm, Phys. Chem. Chem. Phys. 2013, 15, 16065-16073; w) B. Bernet, A. Vasella, Helv. Chim. Acta 2007, 90, 1874-1888.

[4] E. P. Gillis, K. J. Eastman, M. D. Hill, D. J. Donnelly, N. A. Meanwell, J. Med. Chem. 2015, 58, 8315-8359.

[5] M. Morgenthaler, E. Schweizer, A. Hoffmann-Roder, F. Benini, R. E. Martin, G. Jaeschke, B. Wagner, H. Fischer, S. Bendels, D. Zimmerli, J. Schneider, F. Diederich, M. Kansy, K. Muller, ChemMedChem 2007, 2, 1100-1115.

[6] a) M. H. Abraham, P. L. Grellier, D. V. Prior, P. P. Duce, J. J. Morris, P. J. Taylor, J. Chem. Soc., Perkin Trans. 2 1989, 699-711; b) D. Vuluga, J. Legros, B. Crousse, A. M. Z. Slawin, C. Laurence, P. Nicolet, D. Bonnet-Delpon, J. Org. Chem. 2011, 76, 1126-1133; c) J. Graton, F. Besseau, A.-M. Brossard, E. Charpentier, A. Deroche, J.-Y. Le Questel, J. Phys. Chem. A 2013, 117, 13184-13193.

[7] J. Graton, Z. Wang, A.-M. Brossard, D. Goncalves Monteiro, J.-Y. Le Questel, B. Linclau, Angew. Chem., Int. Ed. 2012, 51, 6176-6180.

[8] P. W. Kenny, J. Chem. Inf. Model. 2009, 49, 1234-1244.

[9] a) P. A. Champagne, J. Desroches, J.-F. Paquin, Synthesis 2015, 47, 306-322; b) H.-J. Schneider, Chem. Sci. 2012, 3, 1381-1394; c) J. D. Dunitz, R. Taylor, Chem. Eur. J. 1997, 3, 89-98; d) J. A. K. Howard, V. J. Hoy, D. O'Hagan, G. T. Smith, Tetrahedron 1996, 52, 12613-12622; e) B. E. Smart, J. Fluorine Chem. 2001, 109, 3-11.

[10] H. H. Jensen, L. Lyngbye, M. Bols, Angew. Chem., Int. Ed. 2001, 40, 3447-3449.

[11] F. Weinhold, C. Landis, R, Valency and Bonding. A Natural Bond Orbital Donor-Acceptor Perspective., Cambridge University Press Cambridge, 2005.

[12] E. Bogdan, A. Quarré de Verneuil, F. Besseau, G. Compain, B. Linclau, J.-Y. Le Questel, J. Graton, ChemPhysChem 2016, 17, 2702-2709.

[13] A. Bondi, J. Phys. Chem. 1964, 68, 441-451.
[14] E. A. Basso, L. A. Abiko, G. F. Gauze, R. M. Pontes, J. Org. Chem. 2011, 76, 145-153.

[15] R. J. Abraham, T. A. D. Smith, W. A. Thomas, J. Chem. Soc., Perkin Trans. 2 1996, 1949-1955.

[16] M. P. Freitas, C. F. Tormena, R. Rittner, J. Mol. Struct. 2001, 570, 175180.

[17] Q. A. Huchet, W. B. Schweizer, B. Kuhn, E. M. Carreira, K. Müller, Chem. Eur. J. 2016, 22, 16920-16928.

[18] a) R. F. W. Bader, Chem. Rev. 1991, 91, 893-928; b) R. F. W. Bader, Atoms in Molecules: A Quantum Theory, Clarendon, Oxford, 1994.

[19] a) R. A. Cormanich, M. P. Freitas, C. F. Tormena, R. Rittner, RSC Advances 2012, 2, 4169-4174; b) R. A. Cormanich, R. Rittner, M. P. Freitas, M. Buhl, Phys. Chem. Chem. Phys. 2014, 16, 19212-19217.

[20] M. J. Frisch, G. W. Trucks, H. B. Schlegel, G. E. Scuseria, M. A. Robb, J. R. Cheeseman, G. Scalmani, V. Barone, B. Mennucci, G. A. Petersson, H. Nakatsuji, M. Caricato, X. Li, H. P. Hratchian, A. F. Izmaylov, J. Bloino, G. Zheng, J. L. Sonnenberg, M. Hada, M. Ehara, K. Toyota, R. Fukuda, J. Hasegawa, M. Ishida, T. Nakajima, Y. Honda, O. Kitao, H. Nakai, T. Vreven, J. A. Montgomery Jr., J. E. Peralta, F. Ogliaro, M. J. Bearpark, J. Heyd, E. N. Brothers, K. N. Kudin, V. N. Staroverov, R. Kobayashi, J. Normand, K. Raghavachari, A. P. Rendell, J. C. Burant, S. S. Iyengar, J. Tomasi, M. Cossi, N. Rega, N. J. Millam, M. Klene, J. E. Knox, J. B. Cross, V. Bakken, C. Adamo, J. Jaramillo, R. Gomperts, R. E. Stratmann, O. Yazyev, A. J. Austin, R. Cammi, C. Pomelli, J. W. Ochterski, R. L. Martin, K. Morokuma, V. G. Zakrzewski, G. A. Voth, P. Salvador, J. J. Dannenberg, S. Dapprich, A. D. Daniels, Ö. Farkas, J. B. Foresman, J. V. Ortiz, J. Cioslowski, D. J. Fox, Gaussian 09, Gaussian, Inc. (Wallingford, CT, USA), 2009.

[21] Y. Zhao, D. G. Truhlar, J. Phys. Chem. A 2004, 108, 6908-6918.

[22] A. K. Rappe, C. J. Casewit, K. S. Colwell, W. A. Goddard, III, W. M. Skiff, J. Am. Chem. Soc. 1992, 114, 10024-10035.

[23] E. D. Glendening, J. K. Badenhoop, A. E. Reed, J. E. Carpenter, J. A. Bohmann, C. M. Morales, L. C. R., F. Weinhold, Natural Bond Orbital (NBO) version 6.0, Theoretical Chemistry Institute, University of Wisconsin (Madison), 2013. 


\section{Entry for the Table of Contents}

$$
\uparrow \mathrm{p} K_{\mathrm{AHY}}
$$

Variations in hydrogen-bond $(\mathrm{H}-$ bond) donating capacity of closely related conformationally flexible fluorohydrin diastereomers can be explained by subtle differences in conformational profile and in strengths of $\mathrm{OH} \cdots \mathrm{F}$ intramolecular H-bonding. An (updated) correlation equation enabling accurate $\mathrm{H}$-bond donating capacity prediction from a theoretical descriptor is presented.

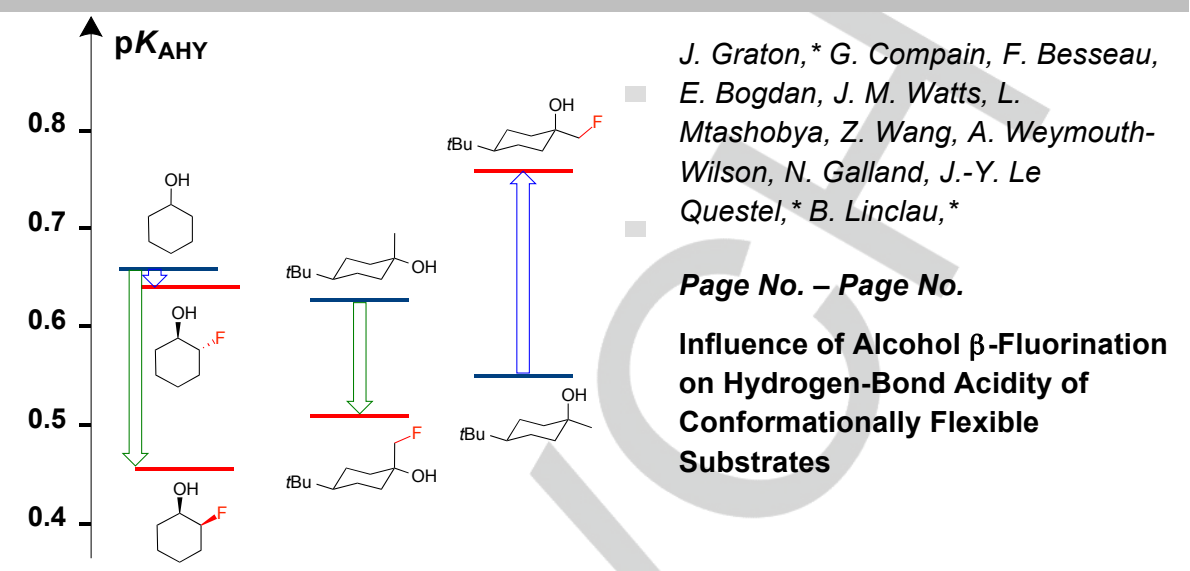

J. Graton, * G. Compain, F. Besseau,

Page No. - Page No.

nfluence of Alcohol $\beta$-Fluorination on Hydrogen-Bond Acidity of Conformationally Flexible Substrates 